\title{
Knowledge Representation Issues in Ontology-based Clinical Knowledge Management Systems
}

\author{
Juan-José Sicilia \\ Hospital Clínico San Carlos \\ Profesor Martín Lagos s/n - 28040 Madrid, SPAIN \\ E-mail: juanjosicilia@gmail.com

\section{Miguel-Angel Sicilia}

Computer Science Department, University of Alcalá, Ctra. Barcelona, km. 33.6 - 28871 Alcalá de Henares (Madrid), SPAIN E-mail: msicilia@uah.es

\section{Salvador Sánchez-Alonso}

Computer Science Department, University of Alcalá, Ctra. Barcelona, km. 33.6 - 28871 Alcalá de Henares (Madrid), SPAIN

E-mail: salvador.sanchez@uah.es

\section{Elena García-Barriocanal}

Computer Science Department, University of Alcalá, Ctra. Barcelona, km. 33.6 - 28871 Alcalá de Henares (Madrid), SPAIN E-mail: elena.garciab@uah.es

\section{Maria Pontikaki}

University of Piraieus

119 Marathonodromon street, tk 11525, Athens, GREECE

E-mail: mariapontikaki@yahoo.com

\begin{abstract}
Knowledge Management in healthcare covers a number of diverse practice activity areas that range from admission and accounting to preventive health programmes. From among these areas, clinical knowledge management represents a specific category that poses differentiated problems and requires specific management support. Clinical knowledge as practiced today mixes formally assessed scientific knowledge with a person-culture in which the expertise of the clinician is the key element. When considering standard Knowledge Management life cycles, this entails that the required processes of creation, assessment and dissemination of clinical knowledge assets diverge from other kind of activities in how different kinds of knowledge are handled. Further, the Information Technology support required for clinical knowledge assets is complex and multi-perspective, thus requiring schemas that integrate formally gathered evidence and subjective practical knowledge. This paper
\end{abstract}




\begin{abstract}
Sicilia
deals with those differences from the viewpoint of formal ontology as a tool to model the specificities of clinical knowledge. An epistemological account of such knowledge is first provided, which serves to delineate how clinical processes and clinical knowledge management could be aligned. The problems of claim evaluation and representation are then approached from that framework, resulting in a realistic integrated set of design guidelines for clinical knowledge management prepared for use in ontology-based Information Systems.
\end{abstract}

Keywords: Healthcare systems, Knowledge Management, clinical knowledge, ontologies.

\title{
1 Introduction
}

Knowledge Management (KM) in healthcare systems encompasses the techniques for the creation, development, dissemination and utilisation of a variety of facets that comprise "healthcare knowledge assets" (Raza Abidi, 2001). Healthcare systems store massive amounts of data of diverse kinds, including patient records, admission information and administrative data, and these data are consequently handled by a variety of professionals. This calls both for specific management methods and also for tools that extract information from these databases. As a matter of fact, there exist proposals for the implementation of KM techniques in the specific environment of healthcare organizations (Raza Abidi, 2001; Bose, 2003), and data mining tools have been applied to large patient data sets as a mean to discover novel clinical disease associations, e.g. (Mullins et al., 2006).

However, clinical knowledge requires a specific approach to KM that differs from that used for other kinds of knowledge assets as those related to administration or benchmarking. Clinical KM is concerned with clinical-based activities (involving healthcare professionals and their direct interaction with patients) while healthcare KM in a broad sense covers also the management of the knowledge in the whole organization, including such aspects as healthcare management and clinical governance. The specificity of clinical KM comes from the fact that clinical knowledge is nowadays considered as a two-faced phenomenon. On the one hand, it comprises the application of sound scientific theory and evidences that are evaluated through the conventional scientific publication process and the methodological norms regulating clinical trials. But on the other hand, clinical KM is also something tied and specific to the experience of the physician, or in some cases, to groups of professionals in concrete healthcare institutions. This "person culture" - in the words of Marshall (1997) - is still an important ingredient of everyday's clinical practice, whose roots can be found in that each individual doctor has her own, idiosyncratic mode of diagnostic reasoning, and in some cases, such mode is not explicit (Sadegh-Zadeh, 2000). If this duality is taken for granted, the dynamics of $\mathrm{KM}$ activities must account for both facets of clinical knowledge and integrate them into a coherent system. This results in both epistemological issues and problems of practical knowledge representation that require specific consideration. 


\section{Ontology based KM in clinical settings}

Epistemological issues are inherent to physicians as healthcare professionals, and the evolution of epistemological thinking is a process that doctor education addresses in some way (Knight and Mattick, 2006). The current epistemological debate in clinical aspects is mostly centred in the evidence-based medicine (EBM) approach to medical practice, often defined as "the conscientious, explicit and judicious use of current best evidence in making decisions about the care of individual patients". A central issue in several EBM approaches is classifying medical evidence in several levels, with data coming from randomized controlled trials considered usually as that of best quality, and anecdotal experience as the less reliable. Even though EBM is not free of controversy and problematic issues (Goldenberg, 2006), it clearly fosters the classification of knowledge of diverse kinds in differentiated categories. Here we do not adhere to a concrete line of epistemological thinking, but assume as factual information that there are different kinds of evidence - as there are different sources - and this is important for the practical management and reuse of clinical information in a broad sense. From a practical perspective, representational issues need to make explicit those different levels, accounts or forms of knowledge and information, which are considered relevant to clinical practice. This is due to the fact that the kind of knowledge asset impacts its use and assessment, which are two key elements in any KM activity model. Existing work has dealt with representing specific forms of elaborated clinical knowledge, as for example, guidelines (Toman, Harrison and Logan, 2001), but here we are concerned with the highlevel categories of knowledge assets that cross-cut different views on clinical practice.

Epistemological and representational issues are of critical importance to clinical KM. KM is a discipline defined by Holsapple and Joshi (2004) as "An entity's systematic and deliberate efforts to expand, cultivate, and apply available knowledge in ways that add value to the entity [. . .]". As a management discipline, KM should provide clinical practice with best practices and techniques that impact the value resulting from the creation, targeted dissemination and reuse of knowledge assets. Chute, Cesnik and van Bemmel (1994) mentioned the importance of designing interfaces that provide an account of different knowledge sources, and Montani and Bellazzi (2002) discussed the usefulness of operational knowledge for case base reasoning in contrast to formalized knowledge as appears in textbooks or guidelines. However, such a complex issue requires a careful re-examination when approaching the design of ontology-based systems aimed at providing general models of the reality of clinical practice represented in logics-based languages. Here we report on a high-level knowledge architecture for ontology-based clinical KM systems that integrates diverging viewpoints, providing a collection of broad design guidelines for the implementation of such kind of systems.

This paper focuses on representational issues of clinical knowledge, standing from a pragmatic position in which it is considered that both broad kinds of clinical knowledge which can be roughly categorized as "objective" and "subjective" - will coexist in actual practice. As a departure assumption for the discussion that follows, it is considered that knowledge will be represented and linked to formal ontologies. Formal ontologies (Baader et al., 2003) are a vehicle for the representation of shared conceptualizations that is useful for technology-intensive organizations. Ontologies based on description logics (Gruber, 1995) or related formalisms provide the added benefit of enabling certain kinds of reasoning over the terms, relations and axioms that describe the domain. A pragmatic benefit of the use of formal ontologies is that it is accompanied by a growing body of 
Sicilia

Semantic Web (Berners-Lee, Lassila and Hendler, 2001) tools, techniques and knowledge. In consequence, modern formal ontology eases the creation of knowledgebased systems as those required for managing clinical information. Ontology is currently being used as an integration of heterogeneous sources (Dogac et al., 2006; Orgun and Vu, 2006) and as a tool to engineer formal knowledge descriptions from existing and diverse medical terminologies (Lee, Supekar and Geller, 2006). We will limit ourselves here to present ontology elements in the aspects that directly relate to the epistemological issues mentioned before.

The rest of this paper is structured as follows. Section 2 discusses the main epistemological issues that must be considered in clinical knowledge for the practical purpose of KM, thus providing a concrete epistemological perspective. Then, the main representational issues using formal ontology are described in Section 3. After that, Section 4 provides a model of knowledge lifecycle for clinical knowledge based on a standard KM lifecycle model. Section 5 deals with the specificities of knowledge claim evaluation according to that lifecycle model. Finally, conclusions and outlook are provided in Section 6.

\section{Some epistemological issues of clinical knowledge}

A preliminary distinction of ontology and epistemology must be made. Ontology starts out from the idea that there are invariants in reality - often called 'classes' - which are captured in the general terms used in the textbooks and which are instantiated by particular examples or cases of such classes, whether these be organisms or organism parts, qualities, functions, processes, diseases or symptoms. In contrast, epistemology in the strict sense is the study of how cognitive subjects come to know the truth (or degree of credibility) about given phenomena in reality. In some cases, epistemological issues are introduced inside ontologies (Bodenreider, Smith and Burgun, 2004). However, this distinction must be considered in the rest of the discussion.

Malterud (2001) described the different views on clinical knowledge and criticized the traditional medical epistemology, resting on a biomedical paradigmatic monopoly, which fails to display an adequate representation of medical knowledge. The following quote explains the essence of his position "clinical knowledge, including the complexities of human interaction, is not available for inquiry by means of biomedical approaches, and consequently is denied legitimacy within a scientific context [...]. Theories of knowledge, especially the concept of tacit knowing, seem suitable for description and discussion of clinical knowledge commonly denoted "the art of medicine"'. This quotation introduces an important element of epistemological controversy that calls for further examination. The rest of this section attempts to describe a pragmatic approach that combines these positions.

A first consideration is defining "clinical knowledge". The Merriam-Webster online Dictionary provides the following definition for the term "clinical":

(1) of, relating to, or conducted in or as if in a clinic: as (a) involving direct observation of the patient (b) diagnosable by or based on clinical observation. 


\section{Ontology based KM in clinical settings}

Thus, the environment of clinical practice is clearly defined, and the main objective of that process is diagnosis. Clinical practice as decision making is obviously based on scientific knowledge of the kind available through standard scientific practice. Evidencebased medicine goes a step further in emphasizing that connection. The term "evidencebased medicine", and its standard definition as "the conscientious, explicit, and judicious use of current best evidence in making decisions about the care of individual patients', (Sackett, Rosenberg, Gray, Haynes, \& Richardson, 1996, p. 71) clearly reflects the positive approach of EBM. However, (controlled) subjectivity rises even in evidencebased judgments. These may come from dispute regarding the design of a study on the grounds of measurement error, contaminated solution, poor design, or bias among other factors (Goldenberg, 2006). Further, Information Systems are organized around notions of value (Cronk and Fitzgerald, 1999), and in practical settings individual expertise becomes the key asset. In the words of Sackett et al. (1996), EBM "requires a bottom-up approach that integrates the best external evidence with individual clinical expertise and patient-choice, [...]. External clinical evidence can inform, but can never replace, individual clinical expertise, and it is this expertise that decides whether the external evidence applies to the individual patient at all [...]". This leads to (a) the need of dealing with personal expertise as a valuable knowledge asset, and (b) considering evidence classifications based on quality as something that might vary or be subject to different viewpoints.

In addition, in some cases conflicting knowledge about, for example, treatment protocols might coexist. These controversial views thus require a compromise from the viewpoint of representation. Such compromise can be attained by the systematic representation of conflicting views on the same diagnosis or patient observation. In fact, current formal languages provide the required formal machinery for such task. For example, the concept of microtheory in Cyc (Lenat, 1995) provides such representational mechanism, intended to organise assertions that depend on 'shared set of assumptions on which the truth of the assertions depends'. Definitions inside the same microtheory need to be consistent, but this is not required across microtheories. This enables representing different "evidence level systems" in different microtheories. In addition, from a representation perspective, the speciality of the clinicians has been found to be relevant (Kalf, and Spruijt-Metz, 1996), which points out that a complete profile of the professional staff is valuable, to adequately account for socio-epistemological factors.

From the above discussion and the examination of clinical practice, the following aspects of clinical knowledge can be differentiated:

I. Clinical knowledge requires a priori general knowledge, i.e. required before patient examination, and not tied to particular patients. This includes but is not limited to epidemiological and biostatistical data. This includes formalized knowledge in the sense given by Montani and Bellazzi (2002).

II. Clinical knowledge requires the representation of basic facts about the patients, but also about the professionals, their speciality and the organization in which clinical practice takes place. This is addressed to some extent by models as HL7 that are yet being used for the implementation of health IS, e.g. (Spahni et al., 2006)

III. Clinical knowledge also involves diagnosis and pre- and post- examination (or pre/post- diagnosis) knowledge, which is patient-specific (case based). 


\section{Sicilia}

IV. Clinical knowledge includes procedural knowledge oriented to describe best practice in observation and diagnosis, as synthesised for example in guidelines (Thomas, Harrison and Logan, 2001).

V. Clinical knowledge must be organized to serve diagnostic practice in direct patient observation, as the main value measurement element.

VI. Clinical knowledge in use relies on information with a degree of vagueness and subjectivity. This includes even conflicting hypotheses, cases or views on concrete matters.

From an organizational perspective, diagnosis is the main observable outcome of clinical practice, and it is performative, in the sense that triggers organizational behaviour (Sadegh-Zadeh, 2000). This makes diagnosis (the product) and diagnostics (the process) the main elements in clinical KM to which value assessment should be directed.

Vagueness as inherent in clinical practice has come from the nature of clinical practice, which deals with cases that are often unique and that are mediated both by the experience and understanding of physicians and by what was recorded in patient records, which in many cases relies on the interpretation of tacit information. A recent essay (Seising, 2006) on applying fuzzy set theory to clinical information has rescued the work of Ludwig Fleck, which stated this fact as follows: "Even the very subject of medical cognition differs in principle from that of scientific cognition. A scientist looks for typical, normal phenomena, while a medical man studies precisely the atypical, abnormal, morbid phenomena. And it is evident that he finds on this road a great wealth and range of individuality of these phenomena which form a great number without distinctly delimited units, and abounding in transitional, boundary states. There exists no strict boundary between what is healthy and what is diseased, and one never finds exactly the same clinical picture again". Fuzziness is a facet of imperfection in information (Smets, 1997), including imprecision, uncertainty and inconsistency, but a detailed account of the kinds of imperfection in clinical information is out of the scope of this paper.

These characteristics can be used as requirement for ontological schemas that serve for $\mathrm{KM}$ processes (Sicilia et al., 2006), thus providing an integration of KM and clinical practice that enables the creation of advanced computer tools. This leads to a general principle for clinical KM systems.

Design guideline on aspects in clinical KM [AKM: Ontology-based clinical KM systems require the differentiation of at least four broad categories of knowledge (IIV), an orientation to patient examination and diagnosis as guiding criteria (V) and a built-in account of imperfection in information (VI).

This general design guideline can be further analyzed from the viewpoint of representation, raising more concrete guidelines, as those described below.

\section{Representing codified knowledge claims}

Knowledge claims include any statement or data that is believed to be true. However, claims may result to be false, so that they are subject to evaluation procedures that attempt to falsify it. This responds essentially to the basic scientific epistemology of 


\section{Ontology based KM in clinical settings}

Popper (1977). Different kinds of statements go routinely through different kinds of evaluation, because of their nature, and this makes them of a different quality in clinical practice. Irrespective of the epistemological validity of these different kinds of claims, the important issue from the representational viewpoint is that of distinguishing different types of claims, so that practitioners can make use of them being conscious of their nature as codified knowledge. For example, basic administrative data (included in aspect II mentioned above) go through clerical validation procedures, which are important but out of the scope of actual clinical activities. In contrast, the evaluation of concrete diagnosis criteria is subject to complex techniques as for example consensus reaching methods (Graham, Regehr and Wright, 2003).

The description of knowledge claims by means of domain ontologies is of paramount importance in clinical practice, since physicians' information seeking behaviour has been characterized to be constrained by lack of time to search, forgetfulness, and the belief that there is likely to be no answer (Dawes and Sampson, 2003).

A first distinction is that of separating the entities that exist from statements made about them. This is a distinction that is considered central in "realist ontology" (Smith and Ceusters, 2006), and the paradigm of referent tracking. In short, referent tracking focuses on what is happening on the side of the patient rather than on statements made by clinicians (Rector et al. 1991). Table 1 provides a broad categorization of knowledge claims based on such distinction.

\begin{tabular}{|l|l|l|l|}
\hline \multicolumn{2}{|l|}{ Type } & Example & $\begin{array}{l}\text { Relation to clinical knowledge } \\
\text { characteristics }\end{array}$ \\
\hline $\begin{array}{l}\text { Patient } \\
\text { data }\end{array}$ & $\begin{array}{l}\text { Referent- } \\
\text { based } \\
\text { (PD-RB) }\end{array}$ & $\begin{array}{l}\text { Concrete past data } \\
\text { identified, referent } \\
\text { tracking elements. }\end{array}$ & $\begin{array}{l}\text { Considered in practice as factual, } \\
\text { uncontroversial data, not tied to the } \\
\text { judgement of a clinician (aspect II). }\end{array}$ \\
\cline { 2 - 5 } & $\begin{array}{l}\text { Clinician- } \\
\text { based } \\
\text { (PD-CB) }\end{array}$ & $\begin{array}{l}\text { Diagnosis, diagnostics, } \\
\text { intuitions or } \\
\text { interpretations of } \\
\text { clinicians. }\end{array}$ & $\begin{array}{l}\text { Clinician-created information, } \\
\text { including notably diagnosis but also } \\
\text { observations (aspect III). Subject to } \\
\text { imperfection (aspect VI) }\end{array}$ \\
\hline $\begin{array}{l}\text { General knowledge } \\
\text { (GK) }\end{array}$ & $\begin{array}{l}\text { Knowledge about the } \\
\text { causes of diseases, and } \\
\text { their effective treatments. }\end{array}$ & $\begin{array}{l}\text { General knowledge on diseases, } \\
\text { procedures and treatments, includes } \\
\text { procedural knowledge (aspects I and } \\
\text { IV). Imperfection (VI) is regulated by } \\
\text { methodological research norms. }\end{array}$ \\
\hline
\end{tabular}

Table 1. Types of "knowledge" in the clinical domain w.r.t. its factual consideration

PD-RB knowledge has an administrative focus and thus is of less interest for our present discussion. The central element in clinical KM is diagnosis, since it is actually the reason for treatment and the outcome of patient examination. Diagnosis has been represented as a complex diagnostic structure by Sadegh-Zadeh (2000). The representation of Sadegh-Zadeh introduces an important distinction between diagnosis as the outcome of an inquiry into the patient's health condition on the one hand, and diagnostics as the process of this inquiry on the other hand. Other important distinctions introduced are those of nosological, abnormality and causal diagnosis, and the 


\section{Sicilia}

representation of the pragmatics, e.g. the context and processes of diagnostics. Fuzziness (aspect VI mentioned above) is considered in relevant causal relationships.

Table 2 summarizes the main ontological elements required to cover the characteristics I-VI described earlier, and identifies the relationship to Sadegh-Zadeh representation schema, along with links to the OpenCyc knowledge base, as a way to clarify the computational semantics of each term. The importance of each of such elements for $\mathrm{KM}$ is also sketched. The categories described are intended as an architecture for the representations needed in clinical KM systems.

The consideration of KM introduces a new dimension that is largely unexplored in medical ontologies. KM has been conceptualized in terms of activities (Holsapple and Joshi, 2004), and the elements of such concepts have been formalized in terms of existing ontologies (Sicilia et al., 2006). KM entails a notion of "knowledge asset" that is subject to management activities for the purpose of making it more valuable. In any case, it is clear that clinical knowledge assets are of a various kind and those kinds will be subject to differentiated $\mathrm{KM}$ actions.

General knowledge is not further analyzed in Table 2 since it is not specific to clinical practice, but common to scientific ontology. Burgun (2006) has proposed several desirable characteristics for such ontologies of general medical knowledge: good lexical coverage, good coverage in terms of relations, compatibility with standards, modularity, and ability to represent variation in reality. There are several initiatives in this area, and they provide the terminological framework for describing PD-RB and PD-CB information. It should be noted, however, that there exist a sharp difference between foundational information (e.g. body parts) and hypotheses tested through clinical trials, since the latter require the representation of the significance of the evidence available, from single studies or coming from meta-analysis. GK serves as a global, shared memory for clinical practice. Evidence databases and traditional scholarly archives as MedLine are principal sources for GK. However, a clinical KM system requires pro-active, adaptive retrieval from such sources to aid in diagnostics, and this in turn requires a sort of semantic annotation of these sources. This is a critical issue summarized in the following guideline.

Design guideline on general knowledge integration [GKI]: General Knowledge sources should be integrated with the local clinical context by pulling information adaptively. Medical ontologies provide the mediation capabilities for such connection.

Since clinical practice can be described in its entirety with relation to the human actions carried out by clinicians, an event-based representation should be first examined. OpenCyc ${ }^{1}$ version 1.0 yet provides an event-based characterization of medical care, structured around the class of activities labelled oc_MedicalCareEvent ${ }^{2} \mathbf{s}$ defined as "events in which a medical care professional provides a medical service to some human or animal patient(s)". Despite the obvious fact that we are here concerned with services to

\footnotetext{
${ }^{1} \mathrm{http} / / /$ www.opencyc.org

${ }^{2}$ The "oc_" prefix is used to distinguish OpenCyc constants from other categories in the paper.
} 


\section{Ontology based KM in clinical settings}

humans, this definition serves to record the activities of interest to KM. It should be noted that events in OpenCyc can be complex entities made up of sub-events, which allows for a fine-grained representation of long term activities. Clinical goals are a specific subclass of those activity representations that have been dealt with by Fox et al. (2006) in the context of AI process planning. Observations and evaluations are represented by a subkind of medical care events named oc_MedicalTesting, including common tests as blood tests. Another subkind, oc_MedicalTreatmentEvent, represents the actions taken to alleviate or ameliorate abnormal conditions.

GK used in these kinds of actions might refer either to documents of any kind (oc_InformationBearingThing) or to general medical knowledge codified as propositions (OC_Statement). The latter approach requires representing the knowledge of the diverse medical ontologies in a common form suitable for such kind of specification. Concrete cases used for diagnostic reasoning can be represented in the same way.

Design guideline on activity-based representations [ABR]: Categories of clinical actions are the main ontological building block for recording PD-CB data. Existing event models are rich enough to describe sub-actions, the agents involved, and knowledge used.

Medical diagnosis is the central point of clinical KM. The term oc_MedicalDiagnosis represents the diagnostics process in the sense of SadeghZadeh (2000). However, it is Diagnosis as a statement which can be considered a knowledge asset of a particular character, since it relates a patient to the judgment of a physician. The term oc_PhysiologicalCondition captures abnormal situations, but the broader term Diagnosis is kept to include conjectural diagnosis. This is the essential product of clinical activity and as such it will become the subject of knowledge claim evaluation. The fact that different kinds of statements (including subjective probability) can be found in diagnosis will result in several kinds of evaluation. In any case, the activity-based representation provides traceability of the diagnostics process, which becomes a key element in managing and analyzing the production and evaluation of knowledge (eventually including misdiagnosis).

Design guideline on traceability of diagnosis [TD]: Post-diagnosis actions should be traceable from each diagnosis outcome, thus linking potential misdiagnosis discovery to the causes of the diagnostic process.

Clinical practice also contributes to the creation of general knowledge in scientific form. However, this knowledge is not directly related to the main purpose of healthcare institutions and its value is directly measured in relation to patients. Further, according to models as the KMCI (see Figure 1 below) these can be considered planned Knowledge Production activities, which are not the focus of this paper. However, approaches that emphasize the role of evidence and causal dependencies are quantitative in nature - even though they can be interpreted as fuzzy (Sadegh-Zadeh, 2000) - which requires some numerical representation beyond the symbolic languages of modern ontology languages like OWL. 
Sicilia

Design guideline on numerical handling of evidence [NHE]: Ontology-based clinical KM systems require support for numerical handling of evidence in a broad sense, added to the terminological structures provided by description logics.

The representation of the base information required in clinical KM is centred in the key elements discussed in Table 2 . These are the essential elements to be covered.

Design guideline core ontological elements [COE]: Ontology-based clinical KM requires the representation of patients, physicians, medical care organizations, diagnosis and medical events, clinical procedures and their interrelations. 
Int. J. Technology Management, Vol. X, No. X, xxxx

\begin{tabular}{|c|c|c|c|c|c|}
\hline \multicolumn{2}{|l|}{ Type } & \multirow{2}{*}{$\frac{\text { Element }}{\text { Patient (II, III) }}$} & \multirow{2}{*}{$\begin{array}{l}\text { OpenCyc link } \\
\text { Subsumed by } \\
\text { oc_MedicalPatient }\end{array}$} & \multirow[b]{2}{*}{$\begin{array}{l}\text { Relation to Sadegh-Zadeh schema } \\
\text { Each patient data set } D \text { containing } \\
\text { complaints, symptoms and signs is a } \\
\text { description of a Patient instance, and } \\
\text { also categorical diagnoses that come } \\
\text { from direct measurement. }\end{array}$} & \multirow{2}{*}{$\begin{array}{l}\text { Relevance to KM } \\
\text { Critical as the main management element. } \\
\text { Source of knowledge for personalized KM } \\
\text { (Fierz, 2004). }\end{array}$} \\
\hline $\begin{array}{l}\text { Patient } \\
\text { data }\end{array}$ & $\begin{array}{l}\text { Referent- } \\
\text { based } \\
(\mathrm{PD}-\mathrm{RB})\end{array}$ & & & & \\
\hline & \multirow[t]{5}{*}{$\begin{array}{l}\text { Clinician- } \\
\text { based } \\
\text { (PD-CB) }\end{array}$} & Physician (II) & $\begin{array}{l}\text { Subsumed by oc_Doctor- } \\
\text { Medical }\end{array}$ & Diagnosticians $d_{i}$ in a diagnosis context. & $\begin{array}{l}\text { Important as a basis for performance } \\
\text { evaluation. Source of reputation or } \\
\text { authority for diagnostic information. }\end{array}$ \\
\hline & & $\begin{array}{l}\text { MedicalCareOrganiz } \\
\text { ation (II) }\end{array}$ & $\begin{array}{l}\text { Subsumed by } \\
\text { MedicalCareorganizat } \\
\text { ion }\end{array}$ & $\begin{array}{l}\text { Tacit in the definition of diagnostic } \\
\text { frames }\end{array}$ & $\begin{array}{l}\text { Institutions constraint medical actions due } \\
\text { to its facilities available and goals } \\
\text { pursued. }\end{array}$ \\
\hline & & $\begin{array}{l}\text { Diagnosis (III, V) } \\
\text { (traced though } \\
\text { oc_MedicalCareEven } \\
\text { ts) }\end{array}$ & $\begin{array}{l}\text { In event form: } \\
\text { oc_Medicaldiagnosis } \\
\text { Subsumes } \\
\text { oc_PhysiologicalCond } \\
\text { ition }\end{array}$ & $\begin{array}{l}\text { Categorical and conjectural diagnoses } \\
\text { about a patient, represented as the } \\
\text { diagnosis set } \Delta \text {. }\end{array}$ & $\begin{array}{l}\text { Central concept for the knowledge created } \\
\text { in clinical practice. Essential element in } \\
\text { knowledge claim evaluation. }\end{array}$ \\
\hline & & $\begin{array}{l}\text { ClinicalProcedure } \\
(I V)\end{array}$ & $\begin{array}{l}\text { Subsumed by } \\
\text { oc_MedicalProcedure }\end{array}$ & $\begin{array}{l}\text { Included in the set of methods } M \\
\text { available. }\end{array}$ & $\begin{array}{l}\text { Procedures are knowledge assets that } \\
\text { codify best clinical practice. }\end{array}$ \\
\hline & & $\begin{array}{l}\text { Subjective vagueness } \\
\text { representations (VI) }\end{array}$ & n.a. & $\begin{array}{l}\text { Categorical diagnoses in the form of } \\
\text { membership values, e.g. } \mu_{\mathrm{D}}(\mathrm{p})=0.8 \\
\text { being } p \text { a Patient and } D \text { a concept as an } \\
\text { illness. }\end{array}$ & $\begin{array}{l}\text { Provides the way to model the explicit } \\
\text { vagueness in clinical interpretation } \\
\text { (Seising, 2006) }\end{array}$ \\
\hline $\begin{array}{l}\text { General } \\
(\mathrm{GK})\end{array}$ & knowledge & $\begin{array}{l}\text { Every category of scientific } \\
\text { knowledge that is not tied } \\
\text { to particular patients (I). }\end{array}$ & n.a. & $\begin{array}{l}\text { Source of evidence for causal relevance } \\
\text { relationships }\end{array}$ & $\begin{array}{l}\text { Changing source of base information for } \\
\text { diagnosis, which eventually triggers } \\
\text { reconsideration (evaluation) of diagnosis. }\end{array}$ \\
\hline
\end{tabular}

Table 2. Essential elements required in a representation of clinical knowledge oriented to KM

Copyright (C) 2004 Inderscience Enterprises Ltd. 


\section{Clinical processes as $\mathrm{KM}$ processes}

Models of knowledge creation inside organizations are considered as dynamic processes of development that evolve over time (Cavaleri and Reed, 2000). Such models provide a breakdown of the creation process in terms of concrete processes and elements that drive the overall production of knowledge as targeted to satisfy organizational expectations. For example, the Knowledge Life Cycle (KLC) model of the $\mathrm{KMCI}^{1}$ distinguishes the Knowledge Processing Environment (KPE) from the Business Processing Environment (BPE), describing the latter as the context of actual usage and field assessment of the claims produced and evaluated in the former. This emphasizes the fact that knowledge codified in artefacts as part of Knowledge Production (KP) processes and disseminated as part of Knowledge Integration (KI) processes will be subject to further validation in actual business experience.

Figure 1 provides a clinical interpretation of a KM lifecycle, superimposed to the standard KMCI model.

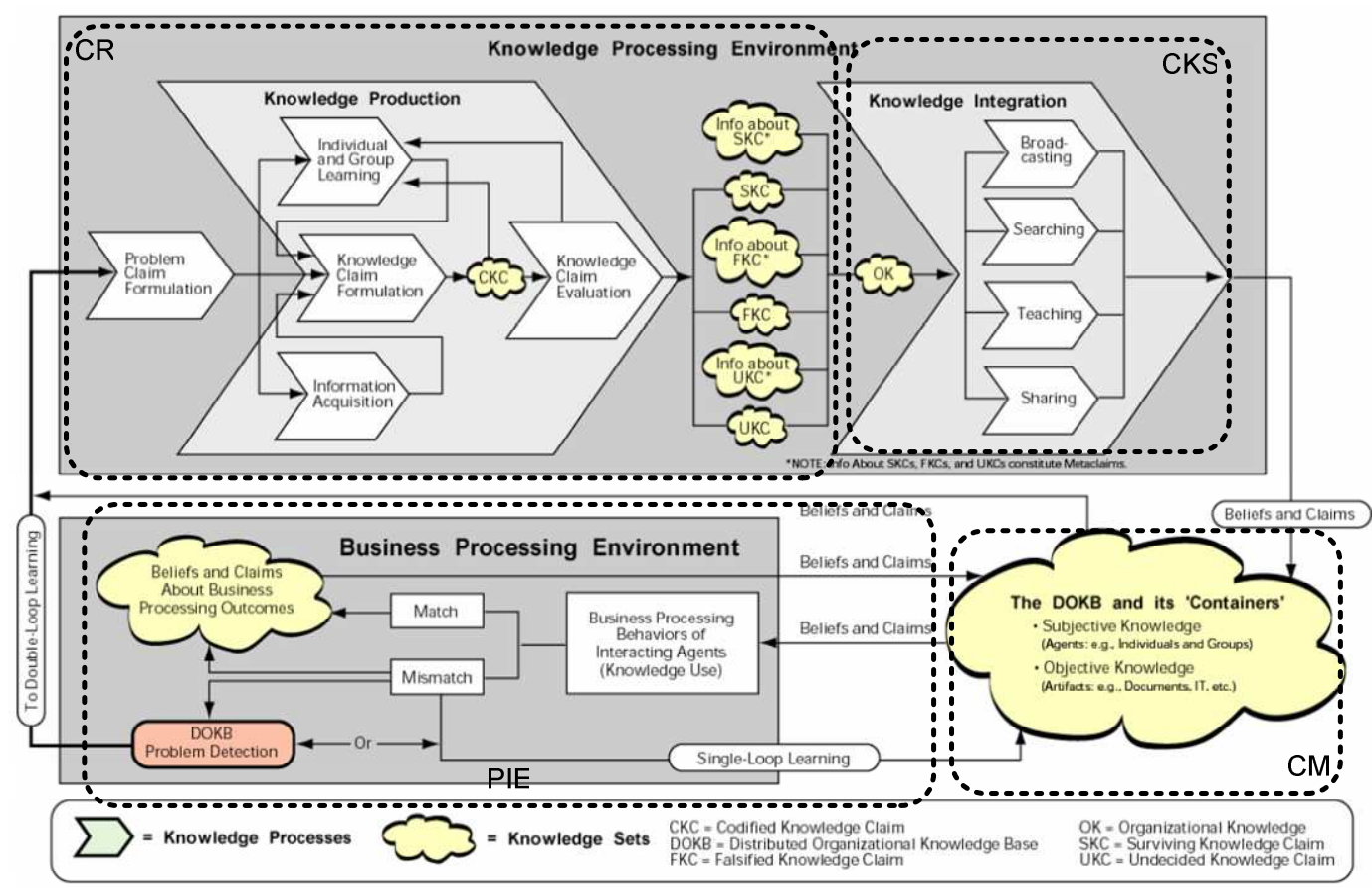

Figure 1. The KMCI model re-interpreted in the clinical KM domain

Figure 1 interprets the "business processing environment" as a "patient interaction environment" (PIE), since the term "business" might be misunderstood in healthcare. In that context, most oc_MedicalCareEvents take place, and Diagnosis are

\footnotetext{
${ }^{1}$ http://www.kmci.org
} 
produced routinely. In that environment, interacting agents are in general healthcare professional (especially Physicians') and Patients, with the former using all the categories of knowledge described in Table 1.

The Distributed Organizational Knowledge Base (DOKB) is considered a Clinical Memory (CM). This component comprises both the full history of patient records and the access to conventional scientific sources of GK (journal, books, databases and the like). The interaction processes produce claims and beliefs about patients (referent-based) and also diagnosis. Form the viewpoint of DOKB problem detection, it is diagnosis which needs to routinely be examined for evaluation. Since every of the other claims and beliefs is produced by activities oriented to diagnostics, the full trace of statements from diagnosis to basic patient profile data should be available [TD]. It should be noted that current administrative practices in many healthcare institutions consist of actually recording that a significant part of it in paper forms or in conventional databases, so recording it in term of ontology languages does not represent a radical change in professional practice.

Clinical Knowledge Sharing (CKS) activities include usual dissemination, search and learning activities that are common to every KM strategy. Knowledge production activities as formally carried out from problem formulations can be considered as Clinical Research (CR) activities. Such research activities involve common clinical practice in the PIE, but they also require activities that are specific to purposeful hypothesis or knowledge validation not tied to the contingent needs of diagnosing or providing treatment to concrete patients. Such additional activities include the preparation of clinical trials or research work that uses medical records as source of data.

\section{Knowledge claim evaluation in the clinical domain}

The evaluation of knowledge claims in the clinical domain can be approached from different methodological standpoints, some of them of a notable sophistication. For example, Kalogeropoulos, Carson and Collinson (2003) describe a concrete method that uses dual-panelled blackboard architecture.

Here we will deal with the general issues of clinical knowledge claims according to the categories of Sadegh-Zadeh. This provides a general framework in which existing concrete techniques can be classified. Table 3 summarizes the main representational issues. It should be noted that GK follows a different evaluation of its knowledge claims. That is, the "Knowledge Claim Evaluation" process in Figure 1, when applied to claims regarding GK and not to particular patients, has two forms of evaluation. On the one hand, the norms and methodological guidelines of research practice entail tests for validating the significance and credibility of hypotheses. On the other hand, such knowledge in its condition of generally applicable is constantly contrasted in clinical practice (as it occurs in the PIE) - eventual mismatch will result in the detection of a problem in the CM. Here we are concerned with the match/mismatch contrast of concrete diagnosis and diagnostic activities as occurs in the PIE.

\footnotetext{
${ }^{1}$ We include in the category of physicians also surgeons, even though the two terms are used in some cases as disjoint categories.
} 


\begin{tabular}{|l|l|l|}
\hline Type & Kind of representation & Evaluation approaches \\
\hline Non-diagnostic & $\begin{array}{l}\text { Come from measurement or direct } \\
\text { statements }\end{array}$ & $\begin{array}{l}\text { (a) Repeated measurement or } \\
\text { predicates related to Patients. }\end{array}$ \\
observation.
\end{tabular}

Table 3. Types of statements and evaluation techniques

The difference between abnormality and diseases is that the latter are typified categories for some combinations of abnormal conditions, for which identifications clinicians require a form of causal relevance judgement.

The representation of different kinds of claims as detailed in Table 3 enables the association of triggers for each type. For example, evaluations of type (c) that result in changes in the current representation of causal relationships should automatically trigger revision procedures for every nosological diagnosis conclusion in which the updated relationship was used as supporting knowledge.

Design guideline on knowledge claim types [KCT]: Knowledge claims should be classified according to their types, thus being connected to different kinds of evaluation or contrast actions applicable.

Evaluation and contrast provide the grounds for supporting diagnostics activities by informing on historical data. From the viewpoint of design of clinical IS, providing information on the contrasts passed by each claim enhances the quality of decision making with evidence data.

Design guideline on communicating evaluation outcomes [KCER]: The results of knowledge claim evaluation processes if available should be communicated as collocated information to each knowledge claim, if relevant. 


\section{Ontology based KM in clinical settings}

The criteria of "relevance" could be stated roughly as follows. For non-diagnostic, categorical information, evaluation results are relevant if negative, since the opposite case represents a mere confirmation of direct observation or measurement. However, both positive and negative results are important in diagnostic information, and also for conjectural information not considered final diagnosis, since the claims are by nature interpretive and thus subject to controversy.

\section{Conclusions and Future Research Directions}

Clinical knowledge management can be considered a part of the broader concept of healthcare KM, in which codified knowledge has specificities related to the special nature of diagnostic activities and the diverse form of diagnosis as the principal part of the knowledge created. The analysis of the kinds of knowledge assets and the kind of evaluations these require has led to a set of design guidelines for clinical KM systems and an account of kinds of knowledge assets used in that context. Such guidelines and principles could also be used for the evaluation of existing KM systems in the clinical domain or as criteria to assess the utility of tools for that specific context. In any case, the tentative ontological schema sketched in this paper can be used as a basis for discussion, enhancement or even replacement.

Future work in the area of clinical KM systems should deal with the appropriate user interfaces for the search and update of information especially in the Patient Interaction Environment. Such user interface design must be able to adequately inform clinicians of the nature and status of the information presented, including the outcomes of evaluation processes carried out.

\section{References}

Baader, F., Calvanese, D., McGuinness, D., Nardi, D., Patel-Schneider, P. (eds.). (2003). The Description Logic Handbook. Theory, Implementation and Applications, Cambridge.

Berners-Lee, T., Hendler, J., Lassila, O. (2001). The Semantic Web. Scientific American, 284(5), 34-43.

Bodenreider, O., Smith, B. and Burgun, A. (2004). The Ontology-Epistemology Divide: A Case Study in Medical Terminology. In: Achille Varzi and Laure Vieu (eds.), Formal Ontology and Information Systems. Proceedings of the Third International Conference (FOIS 2004), Amsterdam: IOS Press, pp. 185-195.

Bose, R. (2003). Knowledge management-enabled health care management systems: capabilities, infrastructure, and decision-support. Expert Systems with Applications, 24, pp. 59-71.

Burgun, A. (2006). Desiderata for domain reference ontologies in biomedicine. Journal of Biomedical Informatics, 39(3), pp. 307-313

Cavaleri, S. and Reed, F. (2000). Designing Knowledge Creating Processes. Knowledge and Innovation, 1(1).

Chute, C.G., Cesnik, B., van Bemmel, J.H. (1994). Medical data and knowledge management by integrated medical workstations: summary and recommendations. Int J Biomed Comput. 34(1-4), pp. 175-83.

Cronk, M. C. \& Fitzgerald, E. P. (1999). Understanding "IS business value": Derivation of dimensions. Logistics Information Management, 12(1/2), pp. 40-49. 


\section{Sicilia}

Dawes, M. and Sampson, U. (2003). Knowledge management in clinical practice: a systematic review of information seeking behaviour in physicians. International Journal of Medical Informatics 71, pp. 9-15

Dogac, A. et al. (2006) Artemis: Deploying semantically enriched Web services in the healthcare domain. Information Systems, 31(4-5), pp. 321-339

Fierz, W. (2004). Challenge of personalized health care: To what extent is medicine already individualized and what are the future trends? Med Sci Monit, 10(5): RA111-123

Fox, J. et al. (2006) An ontological approach to modelling tasks and goals. Computers in Biology and Medicine, 36(7-8), pp. 837-856

Goldenberg, M. (2006). On evidence and evidence-based medicine: Lessons from the philosophy of science. Social Science \& Medicine, 62(11), pp. 2621-2632

Graham, B., Regehr, G. and Wright, J. (2003). Delphi as a method to establish consensus for diagnostic criteria. Journal of Clinical Epidemiology, 56(12), pp. 1150-1156

Gruber T. (1995). Towards principles for the design of ontologies used for knowledge sharing. International Journal of Human-Computer Studies, 43 (5/6), 907 - 928.

Holsapple, C.W. and Joshi, K.D. (2004). A formal knowledge management ontology: Conduct, activities, resources and influences, Journal of the American Society for Information Science and Technology 55 (7), pp. 593-612.

Kalf, A. and Spruijt-Metz, D. (1996). Variation in diagnoses: Influence of specialists' training on selecting and ranking relevant information in geriatric case vignettes. Social Science \& Medicine, 42(5), pp. 705-712

Kalogeropoulos, D., Carson, E. and Collinson, P. (2003). Towards knowledge-based systems in clinical practice: Development of an integrated clinical information and knowledge management support system. Computer Methods and Programs in Biomedicine, 72(1), pp. $65-80$

Knight, L.V. and Mattick, K. (2006). 'When I first came here, I thought medicine was black and white': Making sense of medical students' ways of knowing. Social Science \& Medicine, 63(4), pp. 1084-1096

Lee, Y., Supekar, K. and Geller, J. (2006). Ontology integration: Experience with medical terminologies. Computers in Biology and Medicine, 36(7-8), pp. 893-919

Lenat, D. (1995). CYC: a large-scale investment in knowledge infrastructure. Communications of the $A C M, 38,11,33-38$.

Marshall T. (1997) Scientific knowledge in medicine: a new clinical epistemology? J Eval Clin Pract., 3(2), pp. 133-138.

Malterud K. (1995). The legitimacy of clinical knowledge: towards a medical epistemology embracing the art of medicine. Theor Med. 16(2), pp. 183-198.

Montani, S. and Bellazzi, R. (2002) Supporting decisions in medical applications: the knowledge management perspective. International Journal of Medical Informatics, 68(1-3), pp. 79-90

Mullins et al., (2006) Data mining and clinical data repositories: Insights from a 667,000 patient data set. Computers in Biology and Medicine, 36(12), pp. 1351-1377

Orgun, B. and Vu, J. (2006). HL7 ontology and mobile agents for interoperability in heterogeneous medical information systems. Computers in Biology and Medicine, 36(7-8), pp. 817-836

K. Popper. (1977) The Logic of Scientific Discovery. Routledge.

Raza Abidi, S. (2001). Knowledge management in healthcare: towards 'knowledge-driven' decision support services. International Journal of Medical Informatics, 63, pp. 5-18. 


\section{Ontology based KM in clinical settings}

Rector AL, Nolan WA, and Kay S. Foundations for an Electronic Medical Record. Methods of Information in Medicine 30: 179-86, 1991.

Sackett, D., Rosenberg, W., Gray, J. A. M., Haynes, B., \& Richardson, W. S. (1996). Evidencebased medicine: What it is and what it isn't. British Medical Journal, 312, 71-72.

Sadegh-Zadeh, K. (2000). Fundamentals of clinical methodology: 4. Diagnosis. Artificial Intelligence in Medicine, 20(3), pp. 227-241

Seising R. (2006). From vagueness in medical thought to the foundations of fuzzy reasoning in medical diagnosis. Artificial Intelligence in Medicine (to appear).

Sicilia, M.A., Lytras, M., Rodríguez, E. and García, E. (2006). Integrating Descriptions of Knowledge Management Learning Activities into Large Ontological Structures: A Case Study. Data and Knowledge Engineering, 57(2), pp. 111-121.

Smets, P. (1997). Imperfect information: Imprecision-Uncertainty. In: Uncertainty Management in Information Systems: From Needs to Solutions. Kluwer Academic Publishers, 1997, pp. 225254

Smith B, Ceusters W. Ontology as the Core Discipline of Biomedical Informatics: Legacies of the Past and Recommendations for the Future Direction of Research, forthcoming in Gordana Dodig Crnkovic and Susan Stuart (eds.) Computing, Philosophy, And Cognitive Science, Cambridge: Cambridge Scholars Press, 2006.

Spahni, S. et al. (2006) Implementing a new ADT based on the HL7 version 3 RIM. International Journal of Medical Informatics (in press)

Stefanelli, M. (2001) The socio-organizational age of artificial intelligence in medicine. Artificial Intelligence in Medicine, 23(1), pp. 25-47 